\title{
Precipitation in a Ag-Containing Mg-Y-Zn Alloy
}

\begin{abstract}
Y.M. ZHU, K. OH-ISHI, N.C. WILSON, K. HONO, A.J. MORTON, and J.F. NIE
The precipitation in a $\mathrm{Mg}-6 \mathrm{Y}-2 \mathrm{Ag}-1 \mathrm{Zn}-0.6 \mathrm{Zr}$ (wt pct) alloy during isothermal aging at and above $473 \mathrm{~K}\left(200{ }^{\circ} \mathrm{C}\right)$ has been examined systematically using conventional transmission electron microscopy, high-angle annular dark-field scanning transmission electron microscopy, and three-dimensional atom probe. The precipitation involves the formation of G.P. zones, metastable $\gamma^{\prime \prime}$ and $\gamma^{\prime}$ phases, and equilibrium 14H and $\delta$ phases. The G.P. zones are a single atomic layer on $(0001)_{\alpha}$. The $\gamma^{\prime \prime}$ is the key strengthening phase and it has an ordered hexagonal structure $(P 6 / \mathrm{mmm}, a=0.556 \mathrm{~nm}, c=0.424 \mathrm{~nm})$. The $\gamma^{\prime \prime}$ forms as $(0001)_{\alpha}$ plates with a thickness of a single unit cell height and tends to develop into stacks with irregular spacing when the alloy is exposed to longer aging time at $473 \mathrm{~K}\left(200^{\circ} \mathrm{C}\right)$. The $\gamma^{\prime \prime}$ is gradually replaced by $\gamma^{\prime}$ and $14 \mathrm{H}$ during prolonged aging at $473 \mathrm{~K}\left(200{ }^{\circ} \mathrm{C}\right)$ and/or temperatures above $473 \mathrm{~K}\left(200{ }^{\circ} \mathrm{C}\right)$. The equilibrium $\delta$ phase is also found in grain boundaries. The results are compared with findings in other but similar alloy systems, and approaches for enhancing $\gamma^{\prime \prime}$ nucleation rate and hence further improvement in alloy age-hardening response are discussed. The effects of Ag on precipitation are also discussed.
\end{abstract}

DOI: $10.1007 / \mathrm{s} 11661-015-3251-3$

(C) The Minerals, Metals \& Materials Society and ASM International 2015

\section{INTRODUCTION}

THE development of magnesium alloys with excellent creep resistance and sufficiently high strength at elevated temperature is of the highest importance to meet the requirement of the automobile, aerospace, and aircraft industries. ${ }^{[1,2]}$ Rare-earth (RE) containing magnesium alloys have been recognized as such candidates and thus have received considerable attention in recent years. ${ }^{[3]}$ Most of Mg-RE-based alloys are precipitation hardenable, and the metastable precipitate phases improve the strength and creep resistance of the alloys. Typical commercial and experimental examples are based on the Mg-Y, Mg-Nd, Mg-Gd, Mg-Y-Gd, Mg-Y-Nd, and Mg-Gd-Nd systems. ${ }^{[4-11]}$ Their precipitation sequences have been relatively well established.

In a recent study, ${ }^{[12]}$ ternary additions of $\mathrm{Zn}$ to $\mathrm{Mg}-\mathrm{Y}$ alloys were found to yield little improvement in age-hardening response. The microstructure of the ternary $\mathrm{Mg}-\mathrm{Y}-\mathrm{Zn}$ alloys usually contains intermetallic particles or precipitates with $18 \mathrm{R}$ and $14 \mathrm{H}$ structures. ${ }^{[13-19]}$ The crystal structures of the $18 \mathrm{R}$ and $14 \mathrm{H}$ remain controversial. Our recent work ${ }^{[20]}$ indicates that

Y.M. ZHU, Post-Doctoral Fellow, and J.F. NIE, Professor, are with the Department of Materials Science and Engineering, Monash University, Melbourne, VIC 3800, Australia. Contact e-mail: jianfeng. nie@monash.edu K. OH-ISHI, formerly Post Doc with the National Institute for Materials Science, 1-2-1 Sengen, Tsukuba 305-0047, Japan, is now Researcher with Toyota Central R\&D Labs, Nagakute, Japan. N.C. WILSON, Research Scientist, is with CSIRO Manufacturing, Clayton, VIC 3168, Australia. K. HONO, NIMS Fellow and Managing Director of Magnetic Materials Center, is with the National Institute for Materials Science. A.J. MORTON, Senior Research Fellow, is with the Department of Materials Science and Engineering, Monash University, and also with CSIRO Manufacturing.

Manuscript submitted July 29, 2015

Article published online December 14, 2015 both $18 \mathrm{R}$ and $14 \mathrm{H}$ are made of building blocks that have a hexagonal structure with an ABCA stacking sequence of its close-packed planes. The $\mathrm{Y}$ and $\mathrm{Zn}$ atoms mainly enrich in two inner atomic layers. However, Yokobayashi et al. ${ }^{[21]}$ and Egusa et al. ${ }^{[22]}$ pointed out recently that the enrichment of $\mathrm{Y}$ and $\mathrm{Zn}$ atoms occurred in the consecutive four layers of the ABCA building blocks. It seems that the degree of chemical ordering of the $18 \mathrm{R}$ and $14 \mathrm{H}$ phases depends on the composition of the alloys and heat treatment conditions. $^{[23]}$

Precipitation hardening is the most effective way to improve alloy strength. In particular, it was found more than fifty years ago that the addition of $\mathrm{Ag}$ could considerably increase the age-hardening response and hence mechanical properties of $\mathrm{Mg}-\mathrm{Nd}$ alloys and this led to the development of the commercial alloy QE22 $\left(\mathrm{Mg}-2.5 \mathrm{wt}\right.$ petAg-2 wt petNd-0.7 wt petZr). ${ }^{[24]}$ The precipitation process was reported to involve GuinierPreston zones (G.P. zones), two metastable phases designated $\beta$ and $\gamma$ which are responsible for the peak aging, and an equilibrium phase. ${ }^{[25]}$ The metastable phase $\beta$ was initially reported to be hexagonal with lattice parameters $a=0.556 \mathrm{~nm}, c=0.521 \mathrm{~nm}$, and to have the following orientation relationship with the matrix: $(0001)_{\beta} / /(0001)_{\alpha}$ and $\langle 11 \overline{2} 0\rangle_{\beta} / /\langle 10 \overline{1} 0\rangle_{\alpha .}{ }^{[25]}$ However, a relatively recent study ${ }^{[26]}$ reported that the lattice parameters of the hexagonal $\beta$ phase are $a=0.286 \mathrm{~nm}$, $c=0.521 \mathrm{~nm}$. The $\gamma$ phase was also reported to be hexagonal $(a=0.963 \mathrm{~nm}, c=1.035 \mathrm{~nm})$ obeying the following orientation relationship (OR) with the matrix: $(0001)_{\gamma} / /(0001)_{\alpha}$ and $\langle 11 \overline{2} 0\rangle_{\gamma} / /\langle 11 \overline{2} 0\rangle_{\alpha}$. While the equilibrium phase was originally determined to have a composition of $\mathrm{Mg}_{12} \mathrm{Nd}_{2} \mathrm{Ag},{ }^{[25]}$ a recent study reported a composition of $(\mathrm{Mg}, \mathrm{Ag})_{12} \mathrm{Nd}$ and a tetragonal lattice $(a=1.03 \mathrm{~nm}, c=0.59 \mathrm{~nm}) .{ }^{[26]}$ 
A recent investigation has indicated that the addition of $\mathrm{Ag}$ to the $\mathrm{Mg}-\mathrm{Y}-\mathrm{Zn}$ alloys promotes the formation of nano-scale precipitates ${ }^{[12]}$ and provides a remarkable precipitation-hardening response during isothermal aging at $473 \mathrm{~K}\left(200{ }^{\circ} \mathrm{C}\right)$ for $\mathrm{Ag}$ concentrations at and above $2 \mathrm{wt}$ pct. This enhanced hardening response is associated with a dense distribution of nano-scale basal precipitate plates. These nano-scale precipitate plates appear similar to those in the $\mathrm{Mg}-\mathrm{Gd}-\mathrm{Zn}$, Mg-Gd-Ag-Zn, Mg-Ce-Zn, Mg-Nd-Zn, and Mg-Ca-Zn alloys. ${ }^{[27-34]}$ However, the role of $\mathrm{Ag}$ in the precipitation process of the $\mathrm{Mg}-\mathrm{Y}-\mathrm{Ag}-\mathrm{Zn}$ alloys has not been fully investigated, and attempts to further improve alloy age-hardening response require the knowledge of the crystal structure, composition, and thermal stability of the key strengthening precipitate phases and the distribution of $\mathrm{Ag}$ atoms during the precipitation. Therefore, the major aim of this paper is to clarify the crystal structure, chemistry, and stability of the nano-size precipitates and to establish the precise precipitation sequence in the $\mathrm{Mg}-\mathrm{Y}-\mathrm{Ag}-\mathrm{Zn}$ alloy system that can serve as the platform for the selection of additional micro-alloying additions for further improvement of alloy strength.

\section{METHOD}

\section{A. Alloy Preparation and Characterization}

An alloy with nominal composition of Mg-6Y-2Ag$1 \mathrm{Zn}-0.6 \mathrm{Zr}$ (wt pet) [or Mg-1.76Y-0.48Ag-0.40Zn-0.17Zr (at pct)] was prepared from high-purity $\mathrm{Mg}, \mathrm{Zn}, \mathrm{Ag}$ metals, and Mg-25Y and Mg-33Zr (wt pct) master alloys by induction melting in a steel crucible at approximately $1033 \mathrm{~K}\left(760{ }^{\circ} \mathrm{C}\right)$ under an argon atmosphere. The alloy composition will henceforth be given in wt pct. The molten alloy was poured into a pre-heated [around 573 $\mathrm{K}\left(300^{\circ} \mathrm{C}\right)$ ] steel mold coated by graphite. The resulting ingot was cut into rectangular bars with a size of $7 \times 11 \times 25 \mathrm{~mm}^{3}$ by electrical discharge machining. The bars were then embedded in $\mathrm{MgO}$ powder, solution treated for 24 hours at $773 \mathrm{~K}\left(500^{\circ} \mathrm{C}\right)$, cold water quenched, and aged at $473 \mathrm{~K}, 573 \mathrm{~K}$, and $623 \mathrm{~K}$ $\left(200{ }^{\circ} \mathrm{C}, 300{ }^{\circ} \mathrm{C}\right.$, and $\left.350{ }^{\circ} \mathrm{C}\right)$, respectively.

All samples for transmission electron microscopy (TEM) were cut into $0.5 \mathrm{~mm}$ thick slices using Struers Accutom 50. Disks with $3 \mathrm{~mm}$ in diameter were punched from these slices, ground to $0.1 \mathrm{~mm}$ in thickness, and then ion-beam thinned using the precision ion polishing system. The bright-field TEM images were obtained from a Philips CM20 TEM operating at $200 \mathrm{kV}$. High-angle annular dark-field scanning transmission electron microscopy (HAADF-STEM) image ${ }^{[35]}$ were obtained from a Tecnai (G2) F30 operating at $200 \mathrm{kV}$ with a STEM resolution around $0.2 \mathrm{~nm}$ and a double aberration corrected FEI Titan ${ }^{3}$ 80-300 operating at $300 \mathrm{kV}$ with a STEM resolution around $0.12 \mathrm{~nm}$. For clarity, most raw HAADF-STEM images shown in the figures were also processed by masking of diffraction spots in the fast-Fourier transform of the original image and then back-transforming using Gatan Digital Micrograph. For three-dimensional atom probe (3DAP) tips, ${ }^{[36,37]}$ the bulk sample was cut and then mechanically ground to square rods with a dimension of $100 \mu \mathrm{m} \times 100 \mu \mathrm{m} \times 10 \mathrm{~mm}$. They were then sharpened by a micro-electro-polishing technique using a solution of $5 \mathrm{vol}$ pet perchloric acid and $95 \mathrm{vol}$ pet butoxy-ethanol at the voltage of 14 to $20 \mathrm{~V}$. A delay-line tomography atom probe was used to examine the tips and to check the atom images along the $[0001]_{\alpha}$ direction. Atom probe data selections close to [0001] $]_{\alpha}$ were performed by a locally built energy compensated three-dimensional atom probe (EC-3DAP) at 60 $\mathrm{K}\left(-213^{\circ} \mathrm{C}\right)$ in an ultrahigh vacuum condition $\left(<1 \times 10^{-8} \mathrm{~Pa}\right)$, with a voltage pulse fraction of 0.15 and a pulse repetition rate of $600 \mathrm{~Hz}$.

\section{B. DFT Calculations}

Density functional theory (DFT) calculations were performed within the Vienna Ab Initio Simulation Package (VASP) ${ }^{[38]}$ using the Generalized-Gradient Approximation with the exchange-correlation functional of Perdew-Burke-Ernzerhof. ${ }^{[39]}$ Atoms were treated using projector augmented-wave (PAW) pseudo-potentials provided with VASP. ${ }^{[40,41]}$ The $k$-space integrations were performed using a Monkhorst-Pack sampling scheme, ${ }^{[42]}$ with an equivalent $(18 \times 18 \times 12) k$-point mesh in the $\mathrm{Mg}$ unit cell. Geometric relaxations were performed using a conjugate gradient algorithm with the relaxations terminated when the forces on all atoms decreased below $0.008 \mathrm{eV} / \AA$ A. Formation energies $\left(E_{\text {form }}\right)$ were calculated relative to metallic $\mathrm{Mg}, \mathrm{Y}, \mathrm{Ag}$, and $\mathrm{Zn}$ systems using the formula

$$
E_{\text {form }}=E_{\left(\mathrm{E}_{\mathrm{N}_{\mathrm{X}}} \mathrm{E} 2_{\mathrm{N}_{\mathrm{Y}}} \mathrm{M}_{\mathrm{g}_{\mathrm{Z}}}\right)}-N_{\mathrm{X}} E_{\mathrm{E} 1_{1}}^{\mathrm{ref}}-N_{\mathrm{Y}} E_{\mathrm{E} 2_{1}}^{\mathrm{ref}}-N_{\mathrm{X}} E_{\left(\mathrm{M}_{\mathrm{g}_{1}}\right)}^{\mathrm{ref}},
$$

where $E_{\left(\mathrm{E} 1_{\mathrm{N}} \mathrm{E} 2 \mathrm{~N}_{\mathrm{Y}} \mathrm{M}_{\mathrm{g}_{\mathrm{N}}}\right)}$ is the energy of the calculated structure and is the energy of the atomic species in their bulk structures.

\section{RESULTS}

\section{A. General Microstructure During Aging at $473 \mathrm{~K}$ $\left(200{ }^{\circ} \mathrm{C}\right)$}

The aging curves of Mg-6Y alloys, with $\mathrm{Ag}$ and/or $\mathrm{Zn}$ additions, during isothermal aging treatment at $473 \mathrm{~K}$ $\left(200{ }^{\circ} \mathrm{C}\right)$ have been reported in a previous work. ${ }^{[12]}$ The Ag-free Mg-6Y-1Zn-0.6Zr alloy exhibits little age-hardening response during isothermal aging at $473 \mathrm{~K}$ $\left(200{ }^{\circ} \mathrm{C}\right)$, but the addition of $2 \mathrm{wt}$ pct $\mathrm{Ag}$ to the $\mathrm{Mg}-6 \mathrm{Y}-1 \mathrm{Zn}-0.6 \mathrm{Zr}$ alloy gives rise to a remarkable reduction in the number of intermetallic particles retained after solid solution heat treatment at $773 \mathrm{~K}$ $\left(500{ }^{\circ} \mathrm{C}\right)$ and produces a remarkable age-hardening response at $473 \mathrm{~K}\left(200{ }^{\circ} \mathrm{C}\right) .{ }^{[12]} \mathrm{In}$ the present study, the microstructures of the $\mathrm{Mg}-6 \mathrm{Y}-2 \mathrm{Ag}-1 \mathrm{Zn}-0.6 \mathrm{Zr}$ alloy in the under-aged [ 20 hours, $473 \mathrm{~K}\left(200{ }^{\circ} \mathrm{C}\right)$ ], peak-aged [224 hours, $\left.473 \mathrm{~K}\left(200{ }^{\circ} \mathrm{C}\right)\right]$, and over-aged [5800 hours, $473 \mathrm{~K}\left(200{ }^{\circ} \mathrm{C}\right)$ ] samples and samples subjected to 
further aging at $573 \mathrm{~K}$ and $623 \mathrm{~K}\left(300{ }^{\circ} \mathrm{C}\right.$ and $\left.350{ }^{\circ} \mathrm{C}\right)$ were selected for detailed precipitation characterization.

In the microstructure of the sample under-aged at 473 $\mathrm{K}\left(200{ }^{\circ} \mathrm{C}\right)$, sparsely dispersed plate-like precipitates are observed in the matrix region, Figure 1(a). Most of these precipitates form as single plate, with a typical size of around $20 \mathrm{~nm}$ and thickness less than $1 \mathrm{~nm}$, i.e., an aspect ratio larger than 20:1. Strain contrast is observed in the matrix regions surrounding individual plates. The microstructure typical of the sample peak-aged at $473 \mathrm{~K}$ $\left(200{ }^{\circ} \mathrm{C}\right)$ contains a denser distribution of basal precipitate plates, Figure 1(b). In comparison with the single plates observed in the under-aged microstructure, Figure 1(a), many basal precipitate plates form in pairs in the peak-aged microstructure (indicated by red arrows). These plates have now become larger, $\geq 40$ $\mathrm{nm}$. At the same time, the strain contrast becomes more obvious in the matrix regions surrounding the individual and paired plates. After an extended aging time of 5800 hours, Figure 1(c), most of these basal precipitates are now present as clusters. As shown in Figure 1(d), an enlarged image of Figure 1(c), these precipitate plates have a quite small spacing compared to their size. In addition to these plates, some much larger basal plates are also observed either singly or in clusters, Figure 1(c). The thickness of these long basal plates is also less than $1 \mathrm{~nm}$, but their aspect ratio exceeds 1000:1. It is noted that the matrix regions surrounding small precipitate clusters show much stronger strain contrast, see the lower left part of Figure 1(c). However, little strain contrast is observed around the larger basal plates, the upper right part of Figure 1(c).
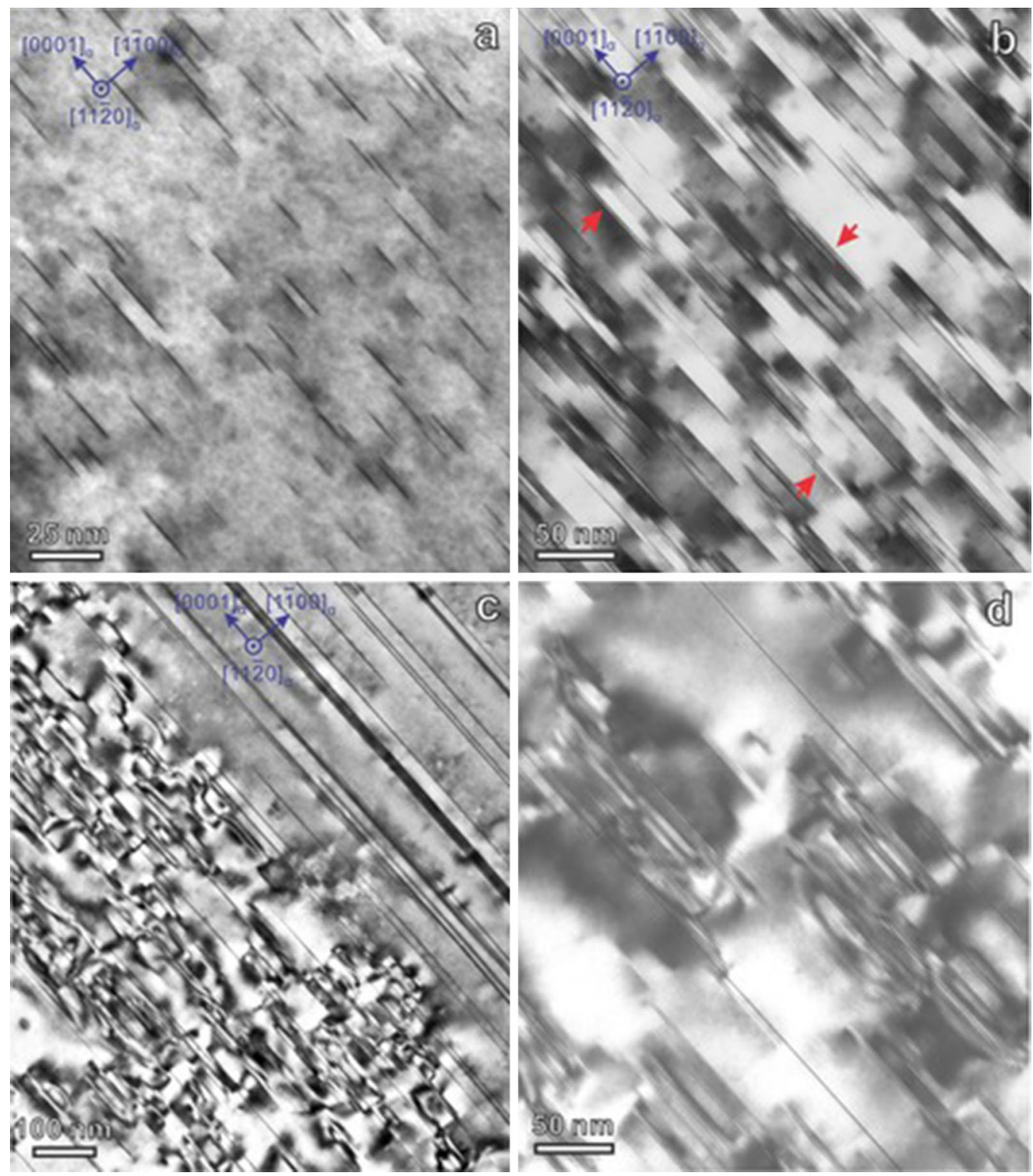

Fig. 1-Bright-field TEM images showing the distributions of precipitates plates in samples of Mg-6Y-2Ag- $1 \mathrm{Zn}-0.6 \mathrm{Zr}$ alloy aged for $(a) 20 \mathrm{~h},(b)$ $224 \mathrm{~h}$, and $(c$ and $d) 5800 \mathrm{~h}$, respectively, at $473 \mathrm{~K}\left(200^{\circ} \mathrm{C}\right)$. The image in $(\mathrm{d})$ is an enlarged part of the lower left region in (c) that contains small precipitate plates. Electron beam is parallel to $\langle 11 \overline{2} 0\rangle_{\alpha}$. 

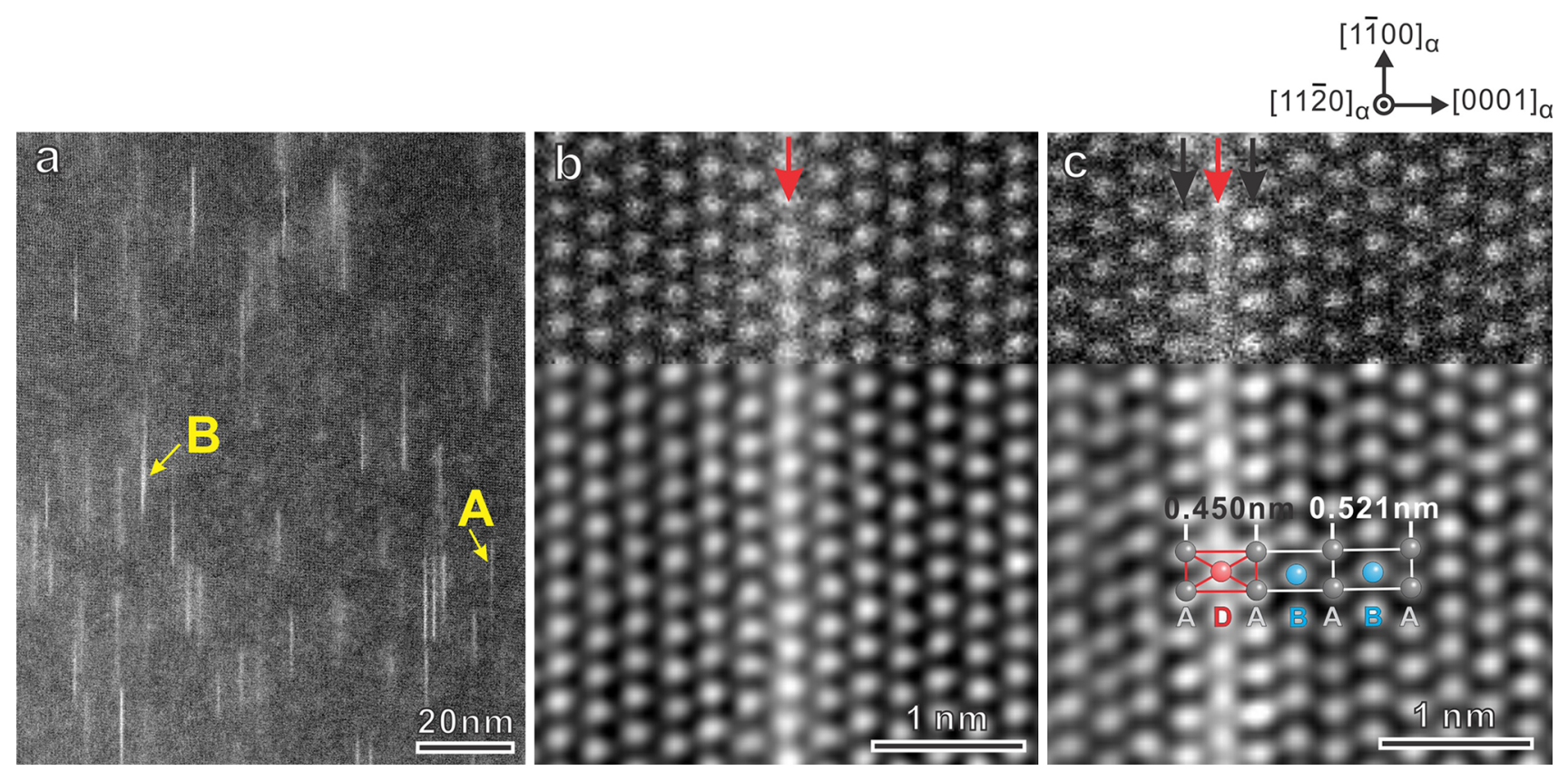

Fig. 2-(a) Low-magnification HAADF-STEM image showing two types of precipitate plates (A and B marked in the image) in an under-aged sample $\left[20 \mathrm{~h} / 473 \mathrm{~K}\left(200^{\circ} \mathrm{C}\right)\right]$ of Mg-6Y-2Ag-1Zn-0.6Zr alloy. Fourier-filtered HAADF-STEM images of $(b)$ an A-type plate having a monolayer of bright atomic columns (G.P. zone) and $(c)$ a B-type plate having three bright atomic layers $\left(\gamma^{\prime \prime}\right)$. The top part in (b or c) is the original HAADF-STEM image, and the rest is the Fourier-filtered image.

\section{B. Under-Aged Microstructure at $473 \mathrm{~K}\left(200^{\circ} \mathrm{C}\right)$}

Following the observations made by conventional TEM, the atomic structures of the precipitates in samples aged under above conditions were examined by HAADF-STEM. A low-magnification $\langle 11 \overline{2} 0\rangle_{\alpha}$ HAADF-STEM image of precipitate plates in a sample under-aged at $473 \mathrm{~K}\left(200{ }^{\circ} \mathrm{C}\right)$ is shown in Figure 2(a). These precipitate plates appear as bright lines, implying a high concentration of $\mathrm{Y}, \mathrm{Ag}$, and/or $\mathrm{Zn}$ atoms in these precipitates (the atomic number is 47 for $\mathrm{Ag}, 39$ for $\mathrm{Y}$, 30 for $\mathrm{Zn}$, and 12 for $\mathrm{Mg}$ ). It is noted that the low addition of $\mathrm{Zr}$ merely plays a role as grain refiner without any precipitation reaction and therefore it will not be considered during the precipitation in this work. Closer inspection of these edge-on plates reveals that the microstructure actually has two different types of plates, which are denoted as $\mathrm{A}$ and $\mathrm{B}$, respectively, in Figure 2(a) with type B plates appearing to be both thicker and brighter than the A-type plates. Figure 2(b) shows an atomic-resolution HAADF-STEM image of an A-type plate viewed along $\langle 11 \overline{2} 0\rangle_{\alpha}$. Inspection of the image reveals immediately that this A-type plate contains a monolayer with bright atomic columns on a single close-packed plane of the $\alpha-\mathrm{Mg}$ lattice, indicated by the red arrow in the image. On the basis of this observation, this A-type plate is suggested to be a G.P. zone. Given the experimental difficulty, it has not been possible to date to clarify the atomic species of the segregated elements in this bright monolayer nor the state of order of these elements. However, it is to be noted that G.P. zones have not been observed in Ag-free
$\mathrm{Mg}-\mathrm{Y}-\mathrm{Zn}$ alloys and hence it is most likely that this bright monolayer is associated with segregation of the Ag atoms.

Figure 2(c) shows a $\langle 11 \overline{2} 0\rangle_{\alpha}$ HAADF-STEM image of a B-type plate. Compared to the bright monolayer of the G.P. zones, it is clear from the image that the B-type precipitate plate contains three adjacent bright atomic layers. For the purpose of clarity, these plate-like precipitates are designated $\gamma^{\prime \prime}$ in order to differentiate them from the G.P. zones. Given that the $\alpha-\mathrm{Mg}$ matrix follows the ABA-type stacking sequence of the close-packed planes, as shown in Figure 2(c), the bright atomic columns in the middle layer of $\gamma^{\prime \prime}$ plate occupy a position different from the "B" layer, marked by the red arrow in the image. Here, this new position is designated as $\mathrm{D}$, which is located at the intersection point of the diagonals in the red-color rectangle frame shown in Figure 2(c). Also, some contrast seems to exist between adjacent bright atomic columns in the D layer, the details of which cannot be resolved probably due to the limited resolution of the microscope. Further examination also indicates that the $\gamma^{\prime \prime}$ plate is coherent with $\alpha-\mathrm{Mg}$ matrix along the $\langle 1 \overline{1} 00\rangle_{\alpha}$ direction. However, the thickness of the $\gamma^{\prime \prime}$ plate along the $[0001]_{\alpha}$ direction, Figure 2(c), is about $0.450 \mathrm{~nm}$ (assuming that $c=0.521 \mathrm{~nm}$ for $\alpha-\mathrm{Mg}$ ). Therefore, a misfit of -0.136 exists between the $\gamma^{\prime \prime}$ and $\alpha-\mathrm{Mg}$ phases along the $[0001]_{\alpha}$ direction. This relatively large misfit may contribute to the apparent strain fields around the $\gamma^{\prime \prime}$ plates observed in the bright-field TEM image in Figure 1(a). 

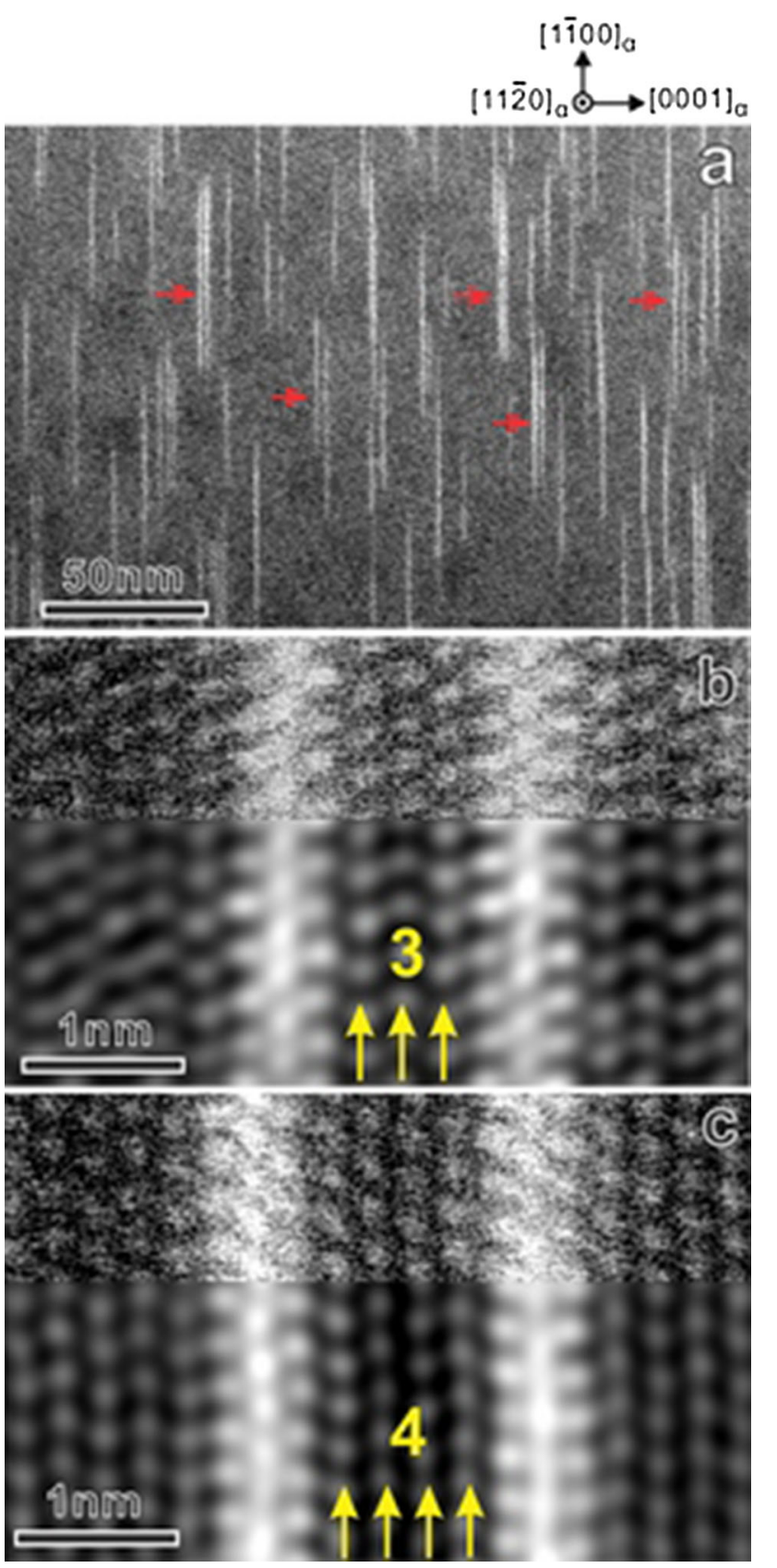

Fig. 3- (a) HAADF-STEM image showing paired $\gamma^{\prime \prime}$ plates in a peak-aged $\left[224 \mathrm{~h} / 473 \mathrm{~K}\left(200^{\circ} \mathrm{C}\right)\right]$ sample of $\mathrm{Mg}-6 \mathrm{Y}-2 \mathrm{Ag}-1 \mathrm{Zn}-0.6 \mathrm{Zr}$ alloy. $(b$ and $c$ ) HAADF-STEM images at atomic resolution showing two distinct plate pairs separated by three and four close-packed $\alpha$-Mg layers, respectively. The top part in (b or c) is the original HAADF-STEM image, and the rest is Fourier-filtered image.

\section{Peak-Aged Microstructure at $473 \mathrm{~K}\left(200^{\circ} \mathrm{C}\right)$}

Figure 3(a) provides a HAADF-STEM image showing the distribution of precipitate plates in a sample peak-aged at $473 \mathrm{~K}\left(200{ }^{\circ} \mathrm{C}\right)$. These precipitate plates exist mainly in pairs (indicated by red arrows in the image), compared to the individual plates in the under-aged microstructure shown in Figure 2(a).

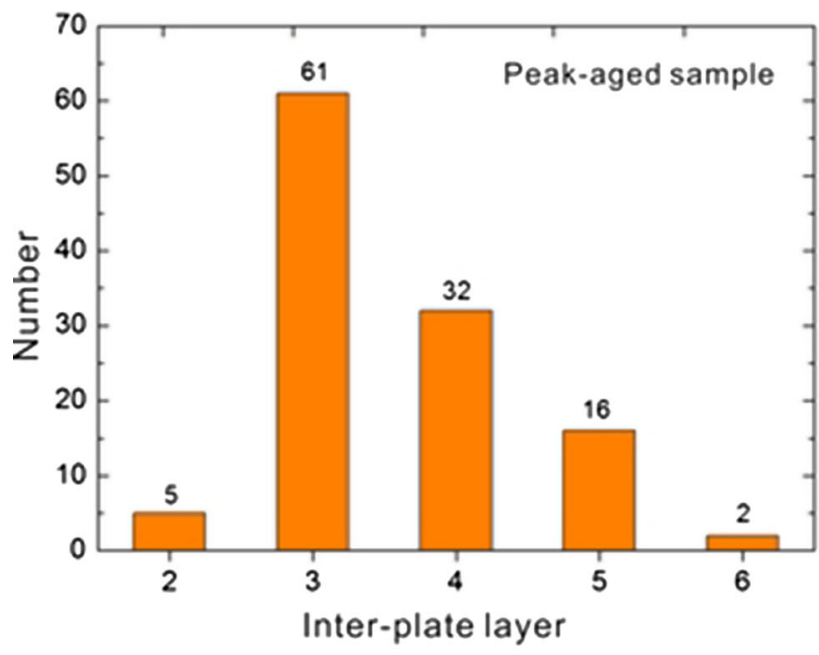

(a)

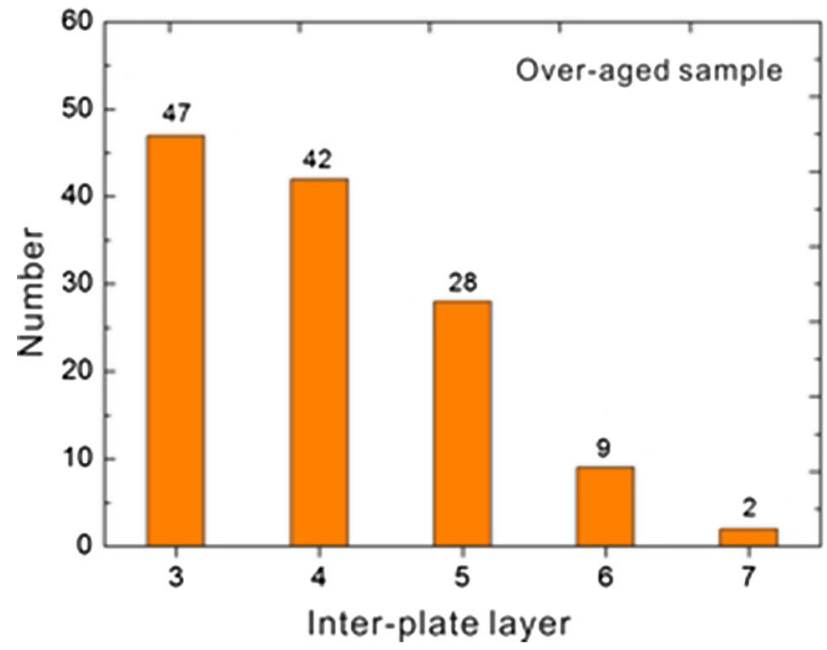

(b)

Fig. 4-Statistic data showing the separation distance between the two plates in each pair in $(a)$ peak-aged $\left[224 \mathrm{~h} / 473 \mathrm{~K}\left(200{ }^{\circ} \mathrm{C}\right)\right]$ and $(b)$ over-aged $\left[5800 \mathrm{~h} / 473 \mathrm{~K}\left(200^{\circ} \mathrm{C}\right)\right]$ samples of $\mathrm{Mg}-6 \mathrm{Y}$ $2 \mathrm{Ag}-1 \mathrm{Zn}-0.6 \mathrm{Zr}$ alloy. The spacing between the two plates is expressed by the number of close-packed planes of $\alpha-\mathrm{Mg}$.

Figures 3(b) and (c) provide atomic-resolution HAADFSTEM images of two distinct plate pairs in Figure 3(a). The structure and the misfit are identical to those of the $\gamma^{\prime \prime}$ plates shown in Figure 2(c). However, the two $\gamma^{\prime \prime}$ plates in Figure 3(b) are separated by three close-packed $\alpha$-Mg layers, in comparison to the four close-packed $\alpha-\mathrm{Mg}$ layers between the two $\gamma^{\prime \prime}$ plates in Figure 3(c). Given that the separation distance between the two plates in each pair varies in the peak-aged microstructure at $473 \mathrm{~K}\left(200{ }^{\circ} \mathrm{C}\right)$, more than 100 pairs of plates were measured to obtain the statistical data of the spacing between the two plates, Figure 4(a). The spacing between the two plates is expressed by the number of the close-packed $\alpha-\mathrm{Mg}$ atomic layers between them. The data clearly show that, even though the paired $\gamma^{\prime \prime}$ plates 
are not regularly spaced; most of them are separated by 3,4 , or $5 \alpha-\mathrm{Mg}$ atomic layers.

\section{Over-aged Microstructure at $473 \mathrm{~K}\left(200^{\circ} \mathrm{C}\right)$}

Figure 5(a) shows a low-magnification HAADFSTEM image of precipitate plates in a sample over-aged at $473 \mathrm{~K}\left(200{ }^{\circ} \mathrm{C}\right)$. The microstructure contains three types of bright precipitate plates. In addition to the small-plate clusters, some much larger basal plates either singly or in clusters are also observed, which is consistent with the microstructure shown in Figure 1(c). The small-plate clusters in Figure 5(a) are firstly examined by atomic-resolution HAADF-STEM imaging along $\langle 11 \overline{2} 0\rangle_{\alpha}$ and $\langle 1 \overline{1} 00\rangle_{\alpha}$ directions, Figures 5(b) and (c), respectively. The image in Figure 5(b) contains five precipitate plates. The separation distance between two neighboring plates is irregular, being $3,3,6$, and 4 close-packed $\alpha$-Mg layers, respectively, in this case. A part of the precipitate plate indicated by the rectangular frame section of Figure 5(b) is enlarged and analysed; see the insert part in Figure 5(b). This plate has three adjacent bright atomic layers, with an ADA-type stacking sequence of the close-packed planes and a misfit (around -0.136 ) with the matrix along $[0001]_{\alpha}$, a result confirmed by the HAADF-STEM image of a $\gamma^{\prime \prime}$ plate along $\langle 1 \overline{1} 00\rangle_{\alpha}$ in Figure 5(c). The structure and the misfit of this plate in Figure 5(b) are both identical to those shown in Figure 2(c).

An atomic-scale HAADF-STEM image of a single large plate observed in Figure 5(a) is shown in Figure 5(d). It is apparent that such precipitates have a different structure from the $\gamma^{\prime \prime}$ phase shown in Figure 5(b). It has an ABCA stacking sequence of the close-packed plane. This precipitate is fully coherent with the surrounding magnesium matrix within the habit plane and in the direction normal to the habit plane. These features of this large plate indicate that it is the $\gamma^{\prime}$ phase that has been reported previously. ${ }^{[1,28]}$ The $\gamma^{\prime}$ phase is also the building block that forms the basis of the unit cells of both $18 \mathrm{R}$ and $14 \mathrm{H}$ phases. ${ }^{[20]}$ Figure 5(e) provides a HAADF-STEM image showing the structure of a cluster of large plates shown in Figure 5(a). In this atomic-resolution image, there are six building blocks. The stacking sequence of the close-packed planes of three blocks is in the opposite direction to that of the other three blocks. By combining two neighboring building blocks together, a $14 \mathrm{H}$ unit cell $^{[20]}$ can be obtained. Therefore, a total of three unit cells of the $14 \mathrm{H}$ structure is obtained, as marked in the image.

As seen in the sample peak-aged at $473 \mathrm{~K}\left(200^{\circ} \mathrm{C}\right)$, the separation distance between two adjacent $\gamma^{\prime \prime}$ plates in the clusters varies and Figure 4(b) provides statistical data made from measurements of more than 50 clusters in the sample over-aged at $473 \mathrm{~K}\left(200{ }^{\circ} \mathrm{C}\right)$. The data clearly confirms that the $\gamma^{\prime \prime}$ plates in each cluster are not regularly spaced and that most of these plates are separated by 3,4 , or $5 \alpha-\mathrm{Mg}$ atomic layers, similar to that observed in the peak-aged sample.
The combined analysis from the HAADF-STEM images and the previously reported selected area electron diffraction (SAED) patterns ${ }^{[12]}$ suggests that the $\gamma^{\prime \prime}$ plates* have a hexagonal structure, with lattice parame-

*The present observations that the $\gamma^{\prime \prime}$ plates are universally one "unit cell" thick put this phase into the class of two-dimensional structures. However, further discussion of this point is not warranted here.

ters $a=0.556 \mathrm{~nm}$ and $c=0.450 \mathrm{~nm}$. The orientation relationship between $\gamma^{\prime \prime}$ and $\alpha-\mathrm{Mg}$ phases is such that $(0001)_{\gamma^{\prime \prime}} / /(0001)_{\alpha}$ and $\langle 10 \overline{1} 0\rangle_{\gamma^{\prime \prime}} / /\langle 2 \overline{1} 10\rangle_{\alpha}$. Figures 6 (a) and (b) shows an atomic model of the possible structure of the $\gamma^{\prime \prime}$ phase. In this model, the unit cell contains six atoms. The positions of these six atoms in the unit cell are $(1 / 3,2$ / $3,0)$ and $(2 / 3,1 / 3,0)$ for $\mathrm{Mg},(0,0,0)$ for $\mathrm{Y}$, and $(0,1 / 2,1 /$ $2),(1 / 2,0,1 / 2)$, and $(1 / 2,1 / 2,1 / 2)$ for $\mathrm{Ag}$. For the current model, we performed geometric relaxation by DFT calculations. The structural model after relaxation projected along $\langle 11 \overline{2} 0\rangle_{\alpha}$ and $\langle 1 \overline{1} 00\rangle_{\alpha}$ directions is shown in Figures 6(c) and (e), respectively. It is interesting to note that $\mathrm{Y}$ atoms move inward compared with the $\alpha-\mathrm{Mg}$ lattice sites in both figures. This feature in Figure 6(e) is in good agreement with the experimental observation along $\langle 1 \overline{1} 00\rangle_{\alpha}$ directions (Figure 6(f)). In Figure 6(c), the inwardly moved $\mathrm{Y}$ atom columns are partially overlapped with $\mathrm{Mg}$ atom columns in this viewing direction which cannot be resolved in the experiment due to the limited resolution of the microscope. However, this overlap can be reflected by the horizontally elongated bright spots in the experimental image in Figure 6(d). In addition, the Ag atom columns as marked by $\mathrm{d} 2$ in Figure 6(d) show brighter contrast than those $\mathrm{Ag}$ atom columns in $\mathrm{d} 1$. This is because the $\mathrm{Ag}$ atom concentration in column $\mathrm{d} 2$ is denser (twice in number density) than that in column $\mathrm{d} 1$. The same reason applies to the contrast difference between Ag columns in $\mathrm{f} 1$ and $\mathrm{f} 2$.

Having shown the fine structure of the $\gamma^{\prime \prime}$ precipitates, the composition of $\gamma^{\prime \prime}$ precipitates is analysed by 3DAP. In the present study, it is difficult to distinguish small $\gamma^{\prime \prime}$ plates from G.P. zones in under-aged samples or the large plates of $\gamma^{\prime}$ and $14 \mathrm{H}$ in over-aged samples in field-ion microscopy (FIM) images and 3DAP maps. However, the $\gamma^{\prime \prime}$ precipitates are the dominant precipitate phase in the peak-aged microstructure. Therefore, the peak-aged samples were selected to obtain FIM images and 3DAP maps. The FIM images of the $\gamma^{\prime \prime}$ precipitates in a peak-aged sample are shown in Figures 7(a) and (b). These images were taken with a mixture of neon and hydrogen as the imaging gas at the temperature of $60 \mathrm{~K}$. When viewed perpendicular to the $[0001]_{\alpha}$ direction, Figure 7(a), bright lines appear in the FIM image. Since $\mathrm{Y}, \mathrm{Ag}$, or $\mathrm{Zn}$ atoms have higher evaporation fields than $\mathrm{Mg}$ atoms, ${ }^{[37]}$ this FIM image indicates that the $\gamma^{\prime \prime}$ plates contain an appreciable concentration of heavy atoms. The morphology of the $\gamma^{\prime \prime}$ phase observed in Figure 7(a) is consistent with that observed by HAADF-STEM imaging in Figure 3(a). The plates become concentric 


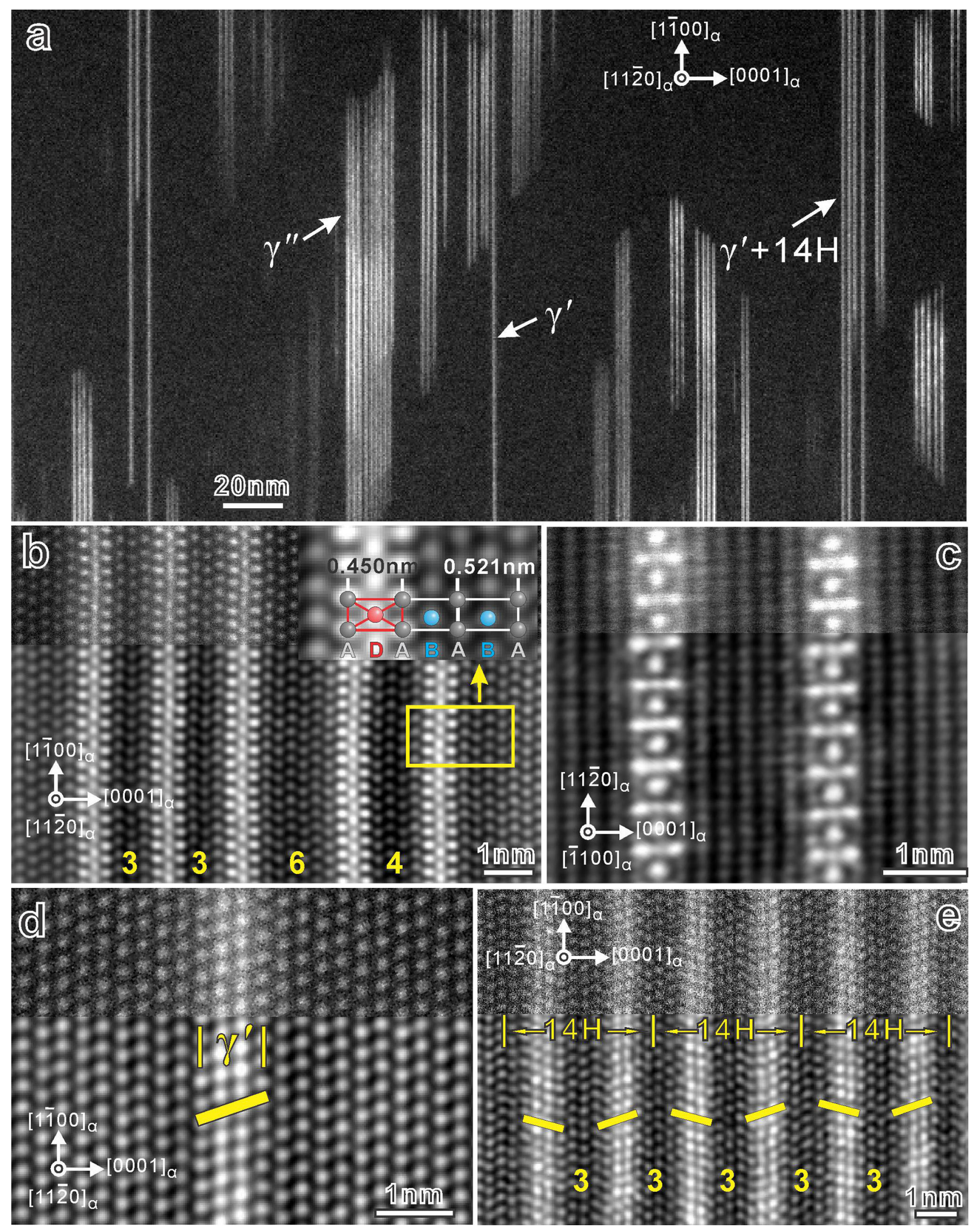

Fig. 5- (a) Low-magnification HAADF-STEM image showing three types of precipitate plates in over-aged $\left[5800 \mathrm{~h} / 473 \mathrm{~K}\left(200{ }^{\circ} \mathrm{C}\right)\right]$ samples. $(b$ and c) HAADF-STEM image showing small precipitate clusters of $\gamma^{\prime \prime}$ phase; the insert image in (b) is from a section of a precipitate plate marked by the rectangular frame. (d) HAADF-STEM image showing a single $\gamma^{\prime}$ plate which is the building block of the 14H; ${ }^{[20]}(e)$ HAADF-STEM image showing precipitate plates of $14 \mathrm{H} \cdot{ }^{[20]}$ The top parts in (b to e) are the original HAADF-STEM image, and the rest is the Fourier-filtered image. 


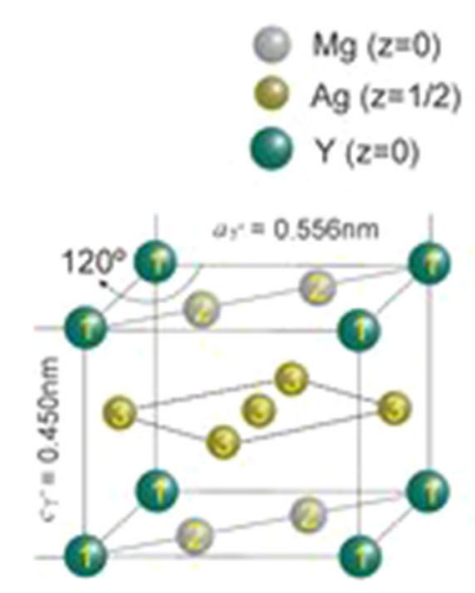

(a)

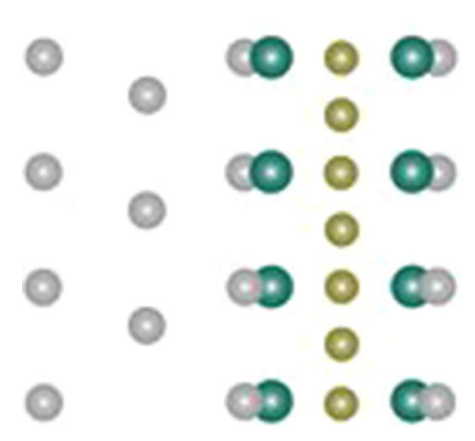

(c)

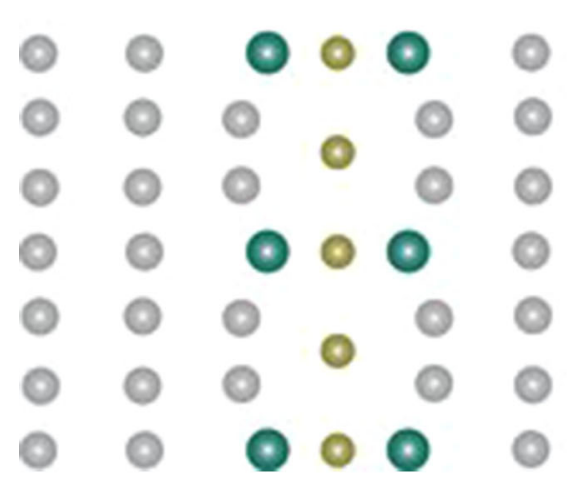

(e)

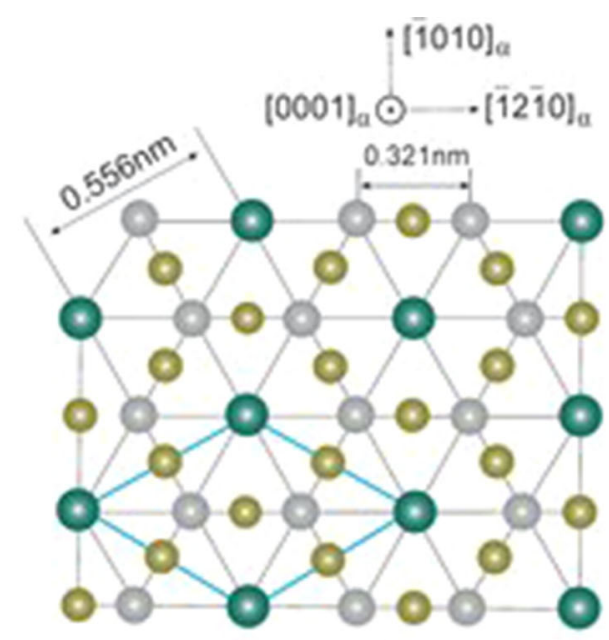

(b)

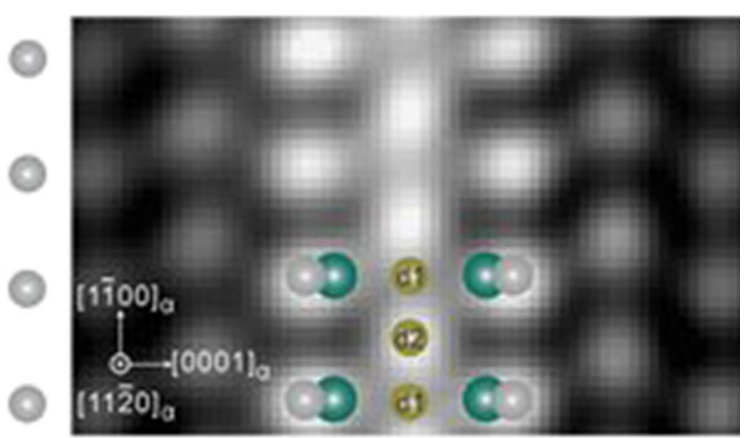

(d)

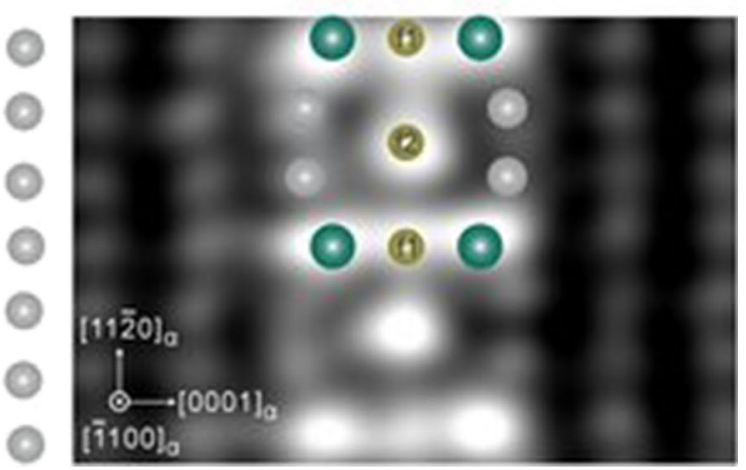

(f)

Fig. 6 - (a) Schematic diagram showing a proposed model for the $\gamma^{\prime \prime}$ unit cell. (b) Perspective view of $\gamma^{\prime \prime}$ structure along the [0001] direction and its relationship with $\alpha$-Mg lattice. Upon geometric relaxation by DFT calculations, the perspective view of the $\gamma^{\prime \prime}$ structure along $(c)\langle 11 \overline{2} 0\rangle_{\alpha}$ and $(e)\langle 1 \overline{1} 00\rangle_{\alpha}$. For comparison, the corresponding experimental image is shown in $(d)$ and $(f)$, respectively.

rings when they are viewed along the $[0001]_{\alpha}$ direction, Figure 7(b). Since these $\gamma^{\prime \prime}$ precipitates are basal plates, most specimens are probed along the $[0001]_{\alpha}$ direction in order to obtain a higher spatial resolution for more accurate data. Figure 7(c) displays 3D reconstruction of a volume selected from a sample peak-aged at $473 \mathrm{~K}$ $\left(200{ }^{\circ} \mathrm{C}\right)$. It shows that many $\gamma^{\prime \prime}$ precipitate plates contain $\mathrm{Y}, \mathrm{Ag}$, and $\mathrm{Zn}$ elements. The measured concentrations of $\mathrm{Y}, \mathrm{Ag}$, and $\mathrm{Zn}$ in the selected particles are approximately 13,6 , and 2.5 at. pct, respectively. Given that the spatial resolution of the $3 \mathrm{D}$ reconstruction map obtained here is not high enough to allow three atomic layers of the $\gamma^{\prime \prime}$ to be recognized, the compositional data of the $\gamma^{\prime \prime}$ is treated as a qualitative result. It should be noted that the composition in the atomic model of the $\gamma^{\prime \prime}$ is different from that by 3DAP. The difference could possibly be attributed to the partial replacement of $\mathrm{Ag}$ atoms in the model by $\mathrm{Mg}$ atoms in the actual $\gamma^{\prime \prime}$ structure. While this possibility could be resolved using a fully quantitative approach to STEM,${ }^{[43]}$ the required analysis of a single atomic column in a relatively thick sample remains a difficult problem. 

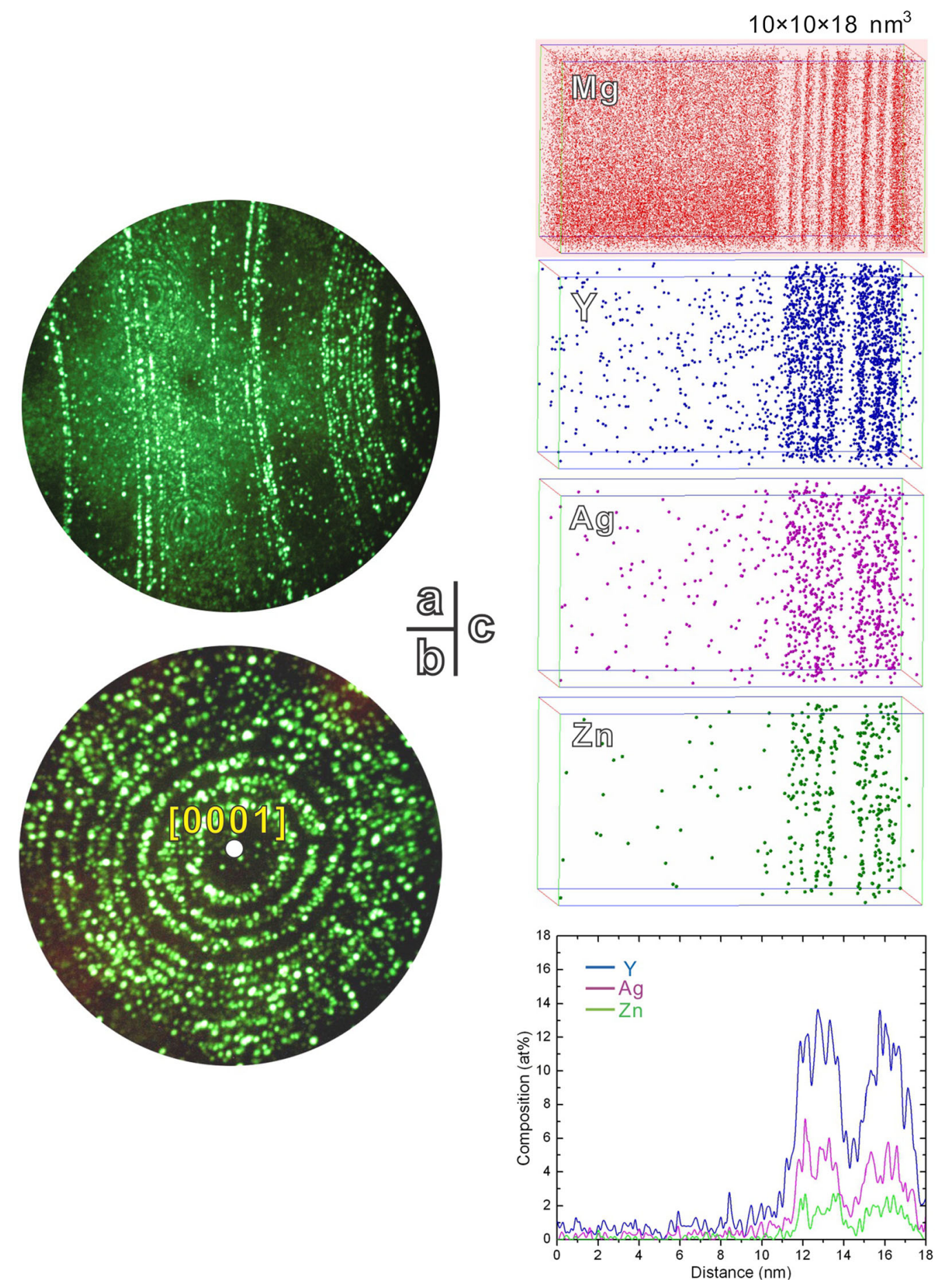

Fig. 7- $(a, b)$ FIM images of $\gamma^{\prime \prime}$ precipitate plates in peak-aged samples $\left[224 \mathrm{~h}\right.$ at $\left.473 \mathrm{~K}\left(200{ }^{\circ} \mathrm{C}\right)\right]$. The viewing direction is perpendicular to $[0001]_{\alpha}$ in (a) and along [0001 $]_{\alpha}$ in (b); (c) 3DAP maps showing distribution of $\mathrm{Y}, \mathrm{Ag}$, and $\mathrm{Zn}$ atoms in $\gamma^{\prime \prime}$ precipitate plates in peak-aged samples.

\section{E. Samples Over-Aged at Temperatures above $473 \mathrm{~K}$ $\left(200{ }^{\circ} \mathrm{C}\right)$}

The over-aged samples [5800 hours/473 $\left.\mathrm{K}\left(200^{\circ} \mathrm{C}\right)\right]$ were re-aged above $473 \mathrm{~K}\left(200^{\circ} \mathrm{C}\right)$ in order to examine the thermal stability of the precipitate plates and to identify the equilibrium phases in the alloy. The microstructure of a re-aged sample [20 minutes at
$573 \mathrm{~K}\left(300^{\circ} \mathrm{C}\right)$ ] is shown in Figure 8. In Figure 8(a), a few precipitate clusters, exhibiting apparent strain contrast, are observed. The fine structure of such a cluster, marked as "A" in Figure 8(a), is shown in Figure 8(b). According to this atomic-scale HAADF-STEM image, it is clear that the cluster is made of three $\gamma^{\prime \prime}$ precipitate plates, with a separation 

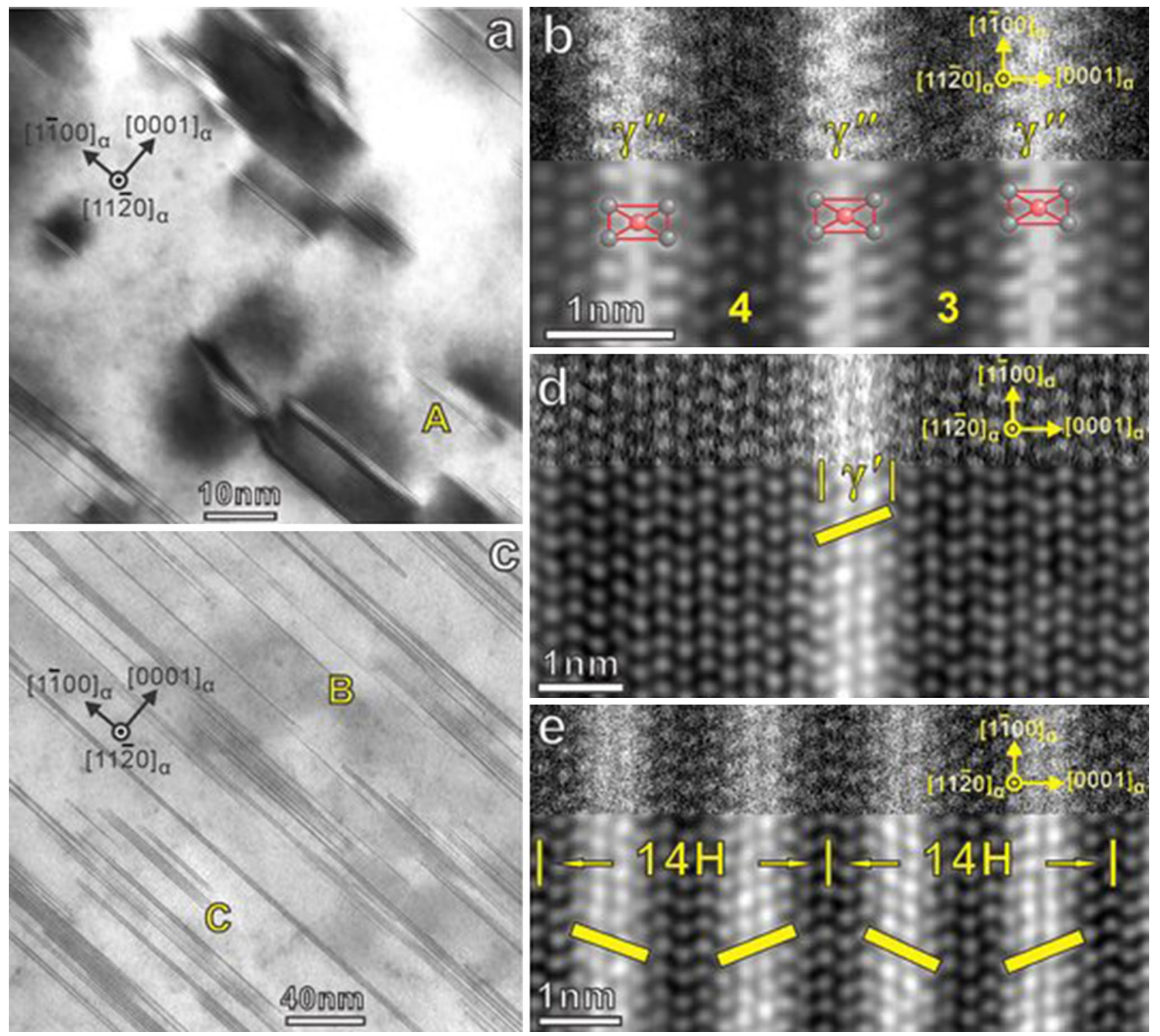

Fig. 8- $(a, c)$ Bright-field TEM images showing the distribution of precipitate plates after a secondary aging for 20 min at $573 \mathrm{~K}\left(300{ }^{\circ} \mathrm{C}\right)$ of over-aged samples [5800 h at $\left.473 \mathrm{~K}\left(200{ }^{\circ} \mathrm{C}\right)\right]$. (b) HAADF-STEM image showing the fine structure of the precipitate plates marked A in (a). $(d$, e) HAADF-STEM images showing structures of precipitate plates marked B and C, respectively, in (c). The top part in (b, d or e) is the original HAADF-STEM image, and the rest is Fourier-filtered image.

distance of 4 and 3 close-packed $\alpha$-Mg layers, respectively, between the neighboring plates. It should be noted that the number density of the $\gamma^{\prime \prime}$ clusters in Figure $8(a)$ is remarkably reduced, compared to those observed before the re-aging treatment, Figures 1(c) and 5(a). On the other hand, most of the area in the microstructure contains precipitate plates without any strain contrast, as shown in Figure 8(c). These plates also form singly, in pairs, or in clusters. Figure 8(d) provides an atomic-resolution HAADF-STEM image of the single large plate labeled B in Figure 8(c). One can immediately notice that this plate is the $\gamma^{\prime}$ phase. It is interesting to note that the morphology of some small-plate groups, such as that labeled $\mathrm{C}$ in Figure 8(c), seems similar to that of the $\gamma^{\prime \prime}$ clusters in Figure 8(a). However, the HAADF-STEM images indicate that this cluster is in fact the $14 \mathrm{H}$ phase, ${ }^{[20]}$ Figure 8(e).

Apart from the microstructural changes that have occurred inside individual grains, some irregular intermetallic particles also appear at grain boundaries, Figure 9. Based on the SAED patterns shown as an inset in the figure, these intermetallic particles are confirmed to be the $\delta$ phase, which has also been reported to exist in the as-cast microstructure. ${ }^{[44]}$ The microstructures shown in Figures 8(a) and (c) show that the number density of the $\gamma^{\prime \prime}$ clusters noticeably decreases after the secondary aging at $573 \mathrm{~K}\left(300{ }^{\circ} \mathrm{C}\right)$ but, at the same time, the number density of the $\gamma^{\prime}$ and $14 \mathrm{H}$ phases increases dramatically, together with the appearance of $\delta$ intermetallic particles along grain boundaries. 


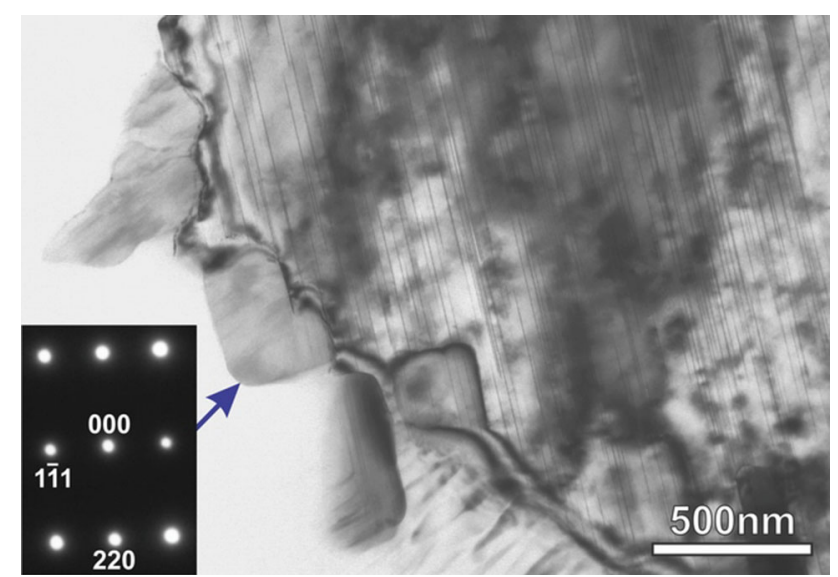

Fig. 9-Bright-field TEM image showing the distribution of intermetallic particles in grain boundaries, and corresponding $\langle\overline{1} 12\rangle$ SAED pattern recorded from one of the intermetallic particles. Sample is over-aged for $5800 \mathrm{~h}$ at $473 \mathrm{~K}\left(200{ }^{\circ} \mathrm{C}\right)$ followed by $20 \mathrm{~min}$ at $573 \mathrm{~K}\left(300^{\circ} \mathrm{C}\right)$.

The over-aged sample $\left[5800\right.$ hours/473 K $\left.\left(200{ }^{\circ} \mathrm{C}\right)\right]$ was also aged at an even higher temperature and the microstructure after a secondary aging for $2 \mathrm{~h}$ at $623 \mathrm{~K}$ $\left(350{ }^{\circ} \mathrm{C}\right.$ ) is shown in Figure 10. In Figure 10(a), many large precipitate plates are observed. They have morphology similar to that observed after the secondary aging at $573 \mathrm{~K}\left(300{ }^{\circ} \mathrm{C}\right)$, Figure $8(\mathrm{c})$. They are confirmed to be $\gamma^{\prime}$ or $14 \mathrm{H}^{[20]}$ No fine-scale $\gamma^{\prime \prime}$ precipitates are observed in this microstructure. In addition, a larger number of $\delta$ intermetallic particles are now observed at grain boundaries, Figure 10(b).

\section{DISCUSSION}

\section{A. Precipitation Sequence}

It has been reported in recent years ${ }^{[45-47]}$ that stacking faults form on the basal plane of the magnesium matrix phase in $\mathrm{Mg}-\mathrm{Y}-\mathrm{Zn}$ and $\mathrm{Mg}-\mathrm{Gd}-\mathrm{Y}-\mathrm{Ag}-\mathrm{Zr}$ alloys. While the stacking faults are not the major features in the $\mathrm{Mg}-\mathrm{Y}-\mathrm{Zn}$ alloy, ${ }^{[45]}$ they were reported to form densely in the $\mathrm{Mg}-\mathrm{Gd}-\mathrm{Y}-\mathrm{Ag}-\mathrm{Zr}$ alloy and therefore are reportedly responsible for the ultrahigh strength of the alloy. ${ }^{[4,47]}$ Even though the alloy system in the present study is similar to that $\mathrm{Mg}-\mathrm{Gd}-\mathrm{Y}-\mathrm{Ag}-\mathrm{Zr}$, most, if not all, platelets formed in the Mg-6Y-2Ag-1Zn-0.6Zr alloy are not stacking faults for the aging conditions studied in the present work. The basal planar features are G.P. zones, $\gamma^{\prime \prime}, \gamma^{\prime}$, and $14 \mathrm{H}$.

The $\gamma^{\prime \prime}$ is the major precipitate phase in the microstructure of the Mg-6Y-2Ag-1Zn-0.6Zr alloy peak-aged at $473 \mathrm{~K}\left(200^{\circ} \mathrm{C}\right)$. However, a secondary aging at $573 \mathrm{~K}\left(300^{\circ} \mathrm{C}\right)$ results in a reduction of $\gamma^{\prime \prime}$ number density, and in association with this phenomenon the volume fraction of $\gamma^{\prime}$ and $14 \mathrm{H}$ phases increases dramatically. After a secondary aging of $623 \mathrm{~K}$ $\left(350{ }^{\circ} \mathrm{C}\right)$, all precipitates of the $\gamma^{\prime \prime}$ phase have disappeared and are replaced by the $\gamma^{\prime}$ and $14 \mathrm{H}$ phases. This microstructural evolution indicates that the $\gamma^{\prime \prime}$ is a metastable phase in the Mg-6Y-2Ag-1Zn-0.6Zr alloy.
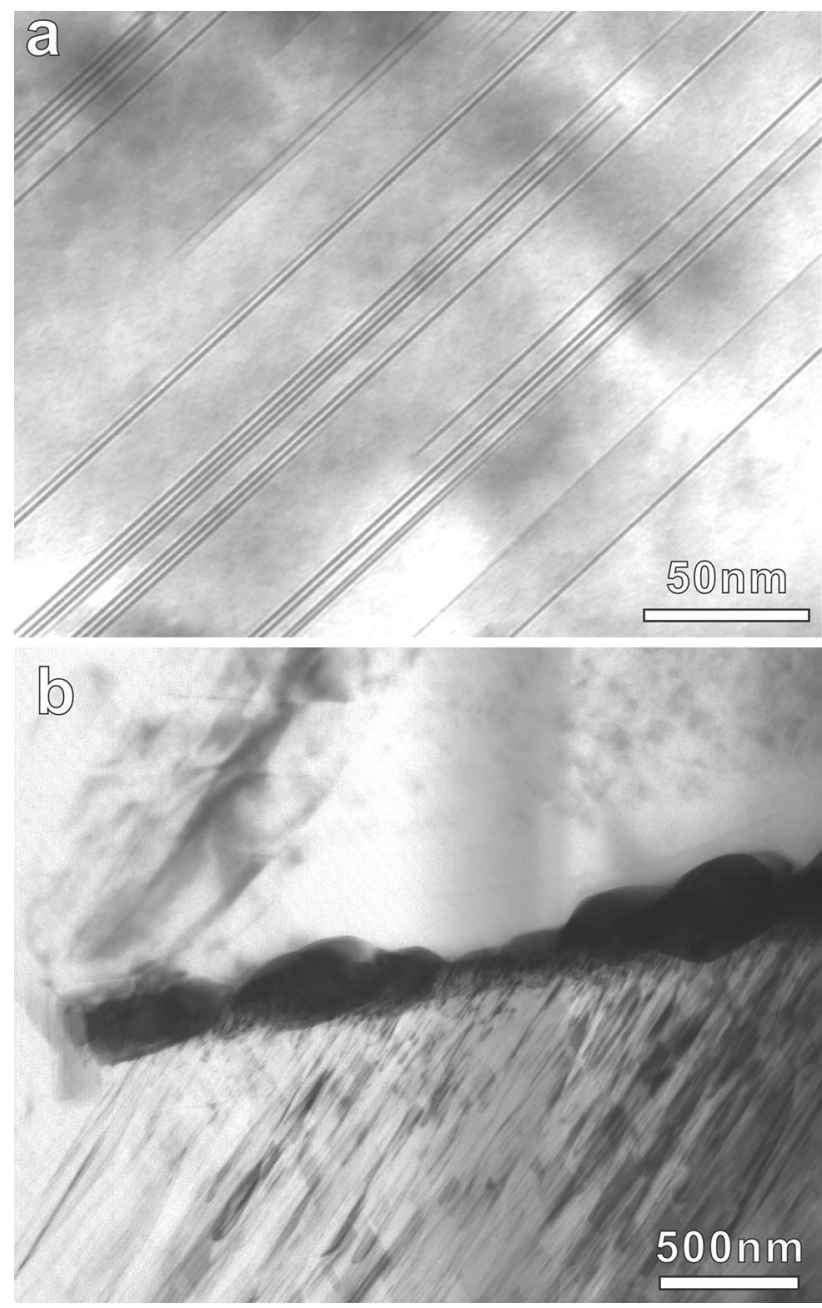

Fig. 10 - Bright-field TEM images showing the distribution of $(a)$ precipitate plates inside a single $\mathrm{Mg}$ grain, and $(b) \delta$ particles at grain boundaries in samples over-aged for $5800 \mathrm{~h}$ at $473 \mathrm{~K}\left(200{ }^{\circ} \mathrm{C}\right)$ followed by a secondary aging for $2 \mathrm{~h}$ at $623 \mathrm{~K}\left(350{ }^{\circ} \mathrm{C}\right)$.

Based on the discussion on the stability and transformation relationship of $\gamma^{\prime}$ and $14 \mathrm{H}$ phases in ternary $\mathrm{Mg}-\mathrm{Y}-\mathrm{Zn}$ alloys, ${ }^{[1,20]}$ the precipitation sequence in the Mg-6Y-2Ag-1Zn-0.6Zr alloy is inferred to be:

Super saturated solid solution $($ SSSS $) \rightarrow$ G.P. zones $\rightarrow \gamma^{\prime \prime} \rightarrow \gamma^{\prime} \rightarrow 14 \mathrm{H}+\delta$

Even though the $\gamma^{\prime}$ phase is also metastable, it is thermally stable during isothermal aging at $623 \mathrm{~K}$ $\left(350{ }^{\circ} \mathrm{C}\right)$. Some particles of the $14 \mathrm{H}^{[20]}$ have formed in the microstructure after prolonged aging (over-aging condition) at $473 \mathrm{~K}\left(200{ }^{\circ} \mathrm{C}\right)$. It is currently difficult to rationalize the observations in different alloys due to a lack of isotherm sections of the $\mathrm{Mg}-\mathrm{Y}-\mathrm{Ag}-\mathrm{Zn}$ phase diagram. Nevertheless, one may conclude that the 573 to $623 \mathrm{~K}\left(300\right.$ to $\left.350{ }^{\circ} \mathrm{C}\right)$ aging temperature range is probably above the solvus line of $\gamma^{\prime \prime}$, but below the solvus line of $\gamma^{\prime}$.

\section{B. Structure of $\gamma^{\prime \prime}$ Precipitates}

The structural model for the $\gamma^{\prime \prime}$ has been proposed in the current work. In order to understand the 


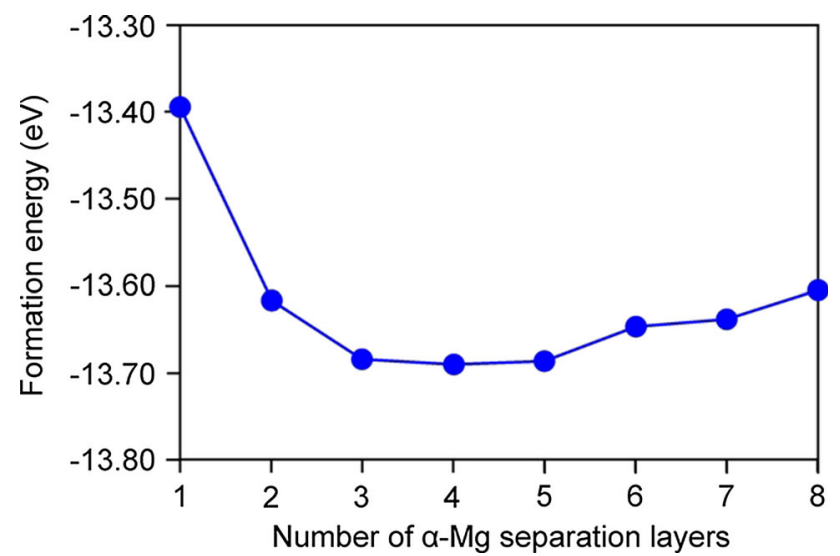

Fig. 11-Formation energies of two $\gamma^{\prime \prime}$ precipitate plates with different numbers of $\alpha$-Mg layers between them.

arrangement of atomic species in the proposed model, further DFT calculations were performed. The equivalent atom sites occupied by $\mathrm{Y}, \mathrm{Mg}$, and $\mathrm{Ag}$ in the unit cell model were labeled as 1, 2, and 3, Figure 6(a). After a series of geometry optimizations were conducted on various combinations of $\mathrm{Ag}, \mathrm{Y}, \mathrm{Mg}$, and $\mathrm{Zn}$ in the three sites, it was found that not all elemental arrangements retained a structure that was consistent with the HAADF-STEM images. Placing $\mathrm{Ag}$ in site $1, \mathrm{Mg}$ in site 2 , and $\mathrm{Y}$ in site 3 , the precipitate phase relaxed to a hexagonal close-packed structure, while placing $\mathrm{Y}$ or $\mathrm{Zn}$ in site 1 with $\mathrm{Mg}$ in site 2 and $\mathrm{Ag}$ in site 3 gave a relaxed structure that had an expansion in the site 1 to 1 distance along [0001 $]_{\alpha}$ at odds with the contraction seen in the experimental results. Filling site 1 with $Y$, site 2 with $\mathrm{Mg}$, and site 3 with either $\mathrm{Ag}$ or $\mathrm{Zn}$ relaxed to structures that were consistent with observation.

Basal plates similar to the $\gamma^{\prime \prime}$ plates in the present work have been observed in the $\mathrm{Mg}-\mathrm{Ce}-\mathrm{Zn}, \mathrm{Mg}-\mathrm{Nd}-\mathrm{Zn}$, Mg-Gd-Zn, and Mg-Ca-Zn alloys. ${ }^{[27-34]}$ However, the present study indicates that the structure of the $\gamma^{\prime \prime}$ phase in the Mg-6Y-2Ag-1Zn-0.6Zr alloy is different in terms of the distribution of solute atoms and the $c$ value of the unit cell. In recent HAADF-STEM observations along $\langle 11 \overline{2} 0\rangle_{\alpha}$ of the Mg-Gd-Zn alloys, ${ }^{[28,48,49]}$ the $\gamma^{\prime \prime}$ phase was reported to contain three atomic layers that have an ABA-type stacking order. In addition, the top and bottom layers are the brightest while the middle layer exhibits brightness at a level between that of the brightest layers and that of $\mathrm{Mg}$ atoms in the matrix. The well-defined structure in the current work also allows the $\gamma^{\prime \prime}$ phase to be distinguished from $\gamma^{\prime}$ or $14 \mathrm{H}$ phase that has the ABCA-type stacking sequence, $\gamma^{\prime}$, or two ABCA-type building blocks that are twin related, $14 \mathrm{H} .^{[20]}$

The $\gamma^{\prime \prime}$ phase almost invariably forms with a thickness that is of a single unit cell height. While it is fully coherent with the matrix in its $(0001)_{\alpha}$ habit plane, a relatively large misfit $(-0.136)$ exists in the direction normal to the habit plane. Therefore, a large volumetric strain is associated with the $\gamma^{\prime \prime}$ formation, which is reflected by the strain contrast in the bright-field TEM images, Figure 1(c). To increase the nucleation rate of the $\gamma^{\prime \prime}$ phase, and hence further enhance the age-hardening response of the alloy, it seems plausible that atoms of additional alloying elements should be larger than $\mathrm{Mg}$ atoms and soluble in the magnesium matrix phase. If such larger atoms segregate to the habit plane of the $\gamma^{\prime \prime}$ plate, then the lattice misfit along the habit plane normal direction will be reduced, leading to a reduction in the activation energy barrier to precipitate nucleation and thus an increase in the nucleation rate of the $\gamma^{\prime \prime}$ phase. An analogous example is the combined additions of micro-alloying elements $\mathrm{Mg}$ and $\mathrm{Ag}$ to precipitation-hardenable $\mathrm{Al}-\mathrm{Cu}$ alloys. In the resultant $\mathrm{Al}-\mathrm{Cu}-\mathrm{Mg}-\mathrm{Ag}$ alloys, the key strengthening precipitate phase is $\Omega$ that forms as plates on $\{111\}_{\alpha}$ planes of the aluminum matrix phase. ${ }^{[50]}$ The $\Omega$ phase has an orthorhombic structure and for its observed orientation relationship with the surrounding aluminum matrix phase, there exists a relatively large misfit $(-0.100)$ in the direction normal to the habit plane. ${ }^{[51]} \mathrm{Mg}$ has larger atomic size than $\mathrm{Al}(0.143 \mathrm{~nm})$, while $\mathrm{Ag}$ has an atomic size similar to $\mathrm{Al}^{\left[{ }^{[52]}\right.}$ Upon aging, the added $\mathrm{Mg}$ and $\mathrm{Ag}$ atoms segregate to the habit plane of $\Omega$ precipitate plates, ${ }^{[53]}$ which reduces the lattice misfit in the plate normal direction. The segregation of $\mathrm{Mg}$ and $\mathrm{Ag}$ to the habit plane of the $\Omega$ plates leads to enhanced nucleation rates and thermal stability of the $\Omega$ plates. ${ }^{[50,54]}$

\section{Distribution of $\gamma^{\prime \prime}$ Precipitates}

The current experimental observations have shown that the $\gamma^{\prime \prime}$ plates in stacks are irregularly spaced but with most plates separated by 3,4 , or $5 \alpha$-Mg atomic layers, either in the peak-aged or over-aged conditions. To examine the effect of increasing separation distance on the stability of the precipitates, a set of calculations were performed where an increasing number of $\alpha$-Mg layers were placed between two adjacent $\gamma^{\prime \prime}$ precipitate plates. The formation energies for the precipitate with $\mathrm{Y}$ in site $1, \mathrm{Mg}$ in site 2, and $\mathrm{Ag}$ in site 3 with the different separations of $\alpha$-Mg layers were plotted in Figure 11. It is obvious that the separation distances of 3, 4, and $5 \mathrm{Mg}$ layers are more favorable than smaller or larger separation distances, which is in qualitative agreement with experimental findings.

Further calculation of a bulk precipitate phase gives a unit cell parameter, $a$, of $0.575 \mathrm{~nm}$ which is larger than the corresponding distance of $0.553 \AA$ in bulk $\alpha-\mathrm{Mg}$. This mismatch will lead to a strain within the precipitate $/ \alpha-\mathrm{Mg}$ structure. Within the calculations, the lattice parameter of $a$ decreased from $5.68 \AA$ with one $\alpha$-Mg layer separation to $5.60 \AA$ with eight-layer separation, while at the same time the width of the precipitate phase in the [0001] direction slightly increased. The balance of strain energy in the precipitate plate versus the strain in the $\mathrm{Mg}$ lattice will form one contribution to the separation of the precipitate plates.

\section{Effect of Ag Additions}

Ternary $\mathrm{Mg}-\mathrm{Y}-\mathrm{Zn}$ alloys exhibit little age-hardening response. This poor age-hardening response is associated with the very limited precipitation of fine-scale precipitates inside individual magnesium grains, the heterogeneous distribution of coarse precipitates in regions adjacent to grain boundaries, and the relatively 
high fraction of retained intermetallic particles after solution treatment. In the Ag-modified alloys, however, the precipitation hardening response is improved remarkably. Unlike the intermetallic particles formed in the Ag-free alloys which are stable and not dissolved by solid solution treatments at $773 \mathrm{~K}\left(500{ }^{\circ} \mathrm{C}\right)$, most intermetallic particles in the Ag-containing alloys dissolve into the matrix after solution treatment at $773 \mathrm{~K}$ $\left(500{ }^{\circ} \mathrm{C}\right)$. This leads to a reduced volume fraction of retained intermetallic particles and thus a higher solute content in the as-quenched microstructure. While it is currently difficult to assess the effects of $\mathrm{Ag}$ on phase equilibria due to the lack of the phase diagram of the $\mathrm{Mg}-\mathrm{Y}-\mathrm{Ag}-\mathrm{Zn}$ system, it is apparent that the Ag additions can enlarge the maximum solid solubility of both $\mathrm{Y}$ and $\mathrm{Zn}$ at the solution treatment temperatures. Apart from a much increased volume fraction of precipitates for artificial aging, the $\mathrm{Ag}$ additions also lead to the formation of G.P. zones and $\gamma^{\prime \prime}$ phase. Both G.P. zones and $\gamma^{\prime \prime}$ phase are more coherent with the magnesium matrix phase than the precipitate phases in the Ag-free counterpart alloy. Combined with a larger driving force for precipitation, there exist smaller activation energy barriers to the nucleation of G.P. zones and $\gamma^{\prime \prime}$, leading to the formation of a denser distribution of such precipitates and thus a stronger age-hardening response.

\section{CONCLUSIONS}

The precipitation process in the Mg-6Y-2Ag- $1 \mathrm{Zn}$ $0.6 \mathrm{Zr}$ alloy prepared by conventional permanent mold casting has been investigated systematically using conventional bright-field TEM, HAADF-STEM imaging, and 3DAP. The results are summarized as the following:

1. The addition of $\mathrm{Ag}$ to $\mathrm{Mg}-\mathrm{Y}-\mathrm{Zn}$ alloys gives rise to a reduced volume fraction of retained intermetallic particles in the solution treated and quenched microstructure resulting in a higher solute content available for precipitation hardening

2. The first stage of the precipitation reaction during isothermal aging at $473 \mathrm{~K}\left(200{ }^{\circ} \mathrm{C}\right)$ is the formation of G.P. zones. The G.P. zones are single atomic plane disks on $(0001)_{\alpha}$.

3. The second stage of the precipitation reaction is the formation of the intermediate $\gamma^{\prime \prime}$ precipitate phase. The $\gamma^{\prime \prime}$ is the key strengthening phase in the alloy. It has an ordered hexagonal structure $(P 6 / \mathrm{mmm}$, $a=0.556 \mathrm{~nm}, c=0.424 \mathrm{~nm})$. The $\gamma^{\prime \prime}$ forms as $(0001)_{\alpha}$ plates with a thickness of a single unit cell height, but it tends to develop into stacks with irregular spacing when the alloy is exposed to prolonged aging at $473 \mathrm{~K}\left(200^{\circ} \mathrm{C}\right)$. The $\gamma^{\prime \prime}$ is gradually replaced by $\gamma^{\prime}$ and $14 \mathrm{H}$ during further aging at $473 \mathrm{~K}\left(200{ }^{\circ} \mathrm{C}\right)$ or aging at temperatures above $473 \mathrm{~K}\left(200{ }^{\circ} \mathrm{C}\right)$.

4. The $\gamma^{\prime}$ has a hexagonal lattice that is similar to that reported in $\mathrm{Mg}-6 \mathrm{Gd}-1 \mathrm{Zn}$ alloy. It has an ABCA stacking sequence of its close-packed planes. Even though the $\gamma^{\prime}$ phase is a metastable phase, it is relatively stable during isothermal aging at $623 \mathrm{~K}$ $\left(350{ }^{\circ} \mathrm{C}\right)$. The temperature range 573 to $623 \mathrm{~K}(300$ to $350{ }^{\circ} \mathrm{C}$ ) is probably above the solvus line of $\gamma^{\prime \prime}$, but below the solvus line of $\gamma^{\prime}$.

5. The equilibrium precipitate phases in the alloy are $14 \mathrm{H}$ and $\delta$.

\section{ACKNOWLEDGMENTS}

The authors wish to acknowledge gratefully the financial support from the Australian Research Council, access to the facilities in the Monash Centre for Electron Microscopy, and computational resources supplied by the National Computational Infrastructure National Facility (NCI-NF).

\section{REFERENCES}

1. I.J. Polmear: Mater. Sci. Tech., 1994, vol. 10, pp. 1-16.

2. B.L. Mordike and K.U. Kainer: Magnesium Alloys and Their Applications, Wiley, New York, 2000.

3. L.L. Rokhlin: Magnesium Alloys Containing Rare Earth Metals, Taylor and Francis, London, 2003.

4. J.F. Nie and B.C. Muddle: Acta Mater., 2000, vol. 48, pp. 1691-1703.

5. T. Honma, T. Ohkubo, K. Hono, and S. Kamado: Mater. Sci. Eng. A, 2005, vol. 395, pp. 301-306.

6. C. Antion, P. Donnadieu, F. Perrard, A. Deschamps, C. Tassin, and A. Pisch: Acta Mater., 2003, vol. 51, pp. 5335-48.

7. X. Gao, S.M. He, X.Q. Zeng, L.M. Peng, W.J. Ding, and J.F. Nie: Mater. Sci. Eng. A, 2006, vol. 431, pp. 322-27.

8. P.J. Apps, H. Karimzadeh, J.F. King, and G.W. Lorimer: Scripta Mater., 2003, vol. 48, pp. 1023-28.

9. I.A. Anyanwu, S. Kamado, and Y. Kojima: Mater. Trans., 2001, vol. 42, pp. 1206-11.

10. S.M. Zhu and J.F. Nie: Scripta Mater., 2004, vol. 50, pp. 51-55.

11. Y.M. Zhu, H. Liu, Z. Xu, Y. Wang, and J.F. Nie: Acta Mater., 2015, vol. 83, pp. 239-47.

12. Y.M. Zhu, A.J. Morton, and J.F. Nie: Scripta Mater., 2008, vol. 58, pp. 525-28.

13. Z.P. Luo and S.Q. Zhang: J. Mater. Sci. Lett., 2000, vol. 19, pp. $813-15$.

14. T. Itoi, T. Seimiya, Y. Kawamura, and M. Hirohashi: Scripta Mater., 2004, vol. 51, pp. 107-11.

15. M. Matsuda, S. Ii, Y. Kawamura, Y. Ikuhara, and M. Nishida: Mater. Sci. Eng. A, 2005, vol. 393, pp. 269-74.

16. A. Ono, E. Abe, T. Itoi, M. Hirohashi, M. Yamasaki, and Y. Kawamura: Mater. Trans., 2008, vol. 49, pp. 990-94.

17. Y.M. Zhu, M. Wayland, A.J. Morton, K. Oh-ishi, K. Hono, and J.F. Nie: Scripta Mater., 2009, vol. 60, pp. 980-83.

18. S. Yoshimoto, M. Yamasaki, and Y. Kawamura: Mater. Trans., 2006, vol. 47, pp. 959-65.

19. J. Lee, K. Sato, T.J. Konno, and K. Hiraga: Mater. Trans., 2009, vol. 50, pp. 222-25.

20. Y.M. Zhu, A.J. Morton, and J.F. Nie: Acta Mater., 2010, vol. 58, pp. 2936-47.

21. H. Yokobayashi, K. Kishida, H. Inui, M. Yamasaki, and Y. Kawamura: Acta Mater., 2011, vol. 59, pp. 7287-99.

22. D. Egusa and E. Abe: Acta Mater., 2012, vol. 60, pp. 166-78.

23. J.F. Nie, Y.M. Zhu, and A.J. Morton: Metall. Mater. Trans. A, 2014, vol. 45, pp. 3338-48.

24. R.J.M. Payne and N. Bailey: J. Inst. Met., 1959-1960, vol. 88, pp. 417-27.

25. I.J. Polmear: Light Alloys, 4th ed., Elsevier/Butterworth-Heinemann, Oxford, 2006.

26. G. Barucca, R. Ferragut, D. Lussana, P. Mengucci, F. Moia, and G. Riontino: Acta Mater., 2009, vol. 57, pp. 4416-25.

27. J.F. Nie, X. Gao, and S.M. Zhu: Scripta Mater., 2005, vol. 53, pp. 1049-53. 
28. J.F. Nie, K. Oh-ishi, X. Gao, and K. Hono: Acta Mater., 2008, vol. 56, pp. 6061-76.

29. X. Gao and J.F. Nie: Scripta Mater., 2008, vol. 58, pp. 619-22.

30. R. Wilson, C.J. Bettles, B.C. Muddle, and J.F. Nie: Mater. Sci. Forum, 2003, vols. 419-422, pp. 267-72.

31. D.H. Ping, K. Hono, and J.F. Nie: Scripta Mater., 2003, vol. 48, pp. 1017-22.

32. C.J. Bettles, K. Venkatesan, and J.F. Nie: Mater. Sci. Forum, 2003, vols. 419-422, pp. 273-78.

33. J.F. Nie and B.C. Muddle: Scripta Mater., 1997, vol. 37, pp. $1475-81$.

34. J.C. Oh, T. Ohkubo, T. Mukai, and K. Hono: Scripta Mater., 2005, vol. 53, pp. 675-79.

35. E.J. Kirkland, R.F. Loane, and J. Silcox: Ultramicroscopy, 1987, vol. 23, pp. 77-96.

36. K. Hono: Prog. Mater. Sci., 2002, vol. 47, pp. 621-29.

37. M.K. Miller, A. Cerezo, M.G. Hetherington, and G.D.W. Smith: Atom Probe Field Ion Microscopy, Cambridge University Press, Cambridge, 1990.

38. G. Kresse and J. Furthmüller: Phys. Rev. B, 1996, vol. 54, pp. 11169-86.

39. J. Perdew, K. Burke, and M. Emzerhof: Phys. Rev. Lett., 1996, vol. 77, pp. 3865-68.

40. P.E. Blochl: Phys. Rev. B, 1994, vol. 50, pp. 17953-79.

41. G. Kresse and D. Joubert: Phys. Rev. B, 1999, vol. 59, pp. 1758-75.

42. J.D. Pack and H.J. Monkhorst: Phys. Rev. B, 1977, vol. 16, pp. $1748-49$.
43. C. Dwyer, C. Maunders, C.L. Zheng, M. Weyland, P.C. Tiemeijer, and J. Etheridge: Appl. Phys. Lett., 2012, vol. 100 (19), p. 191915.

44. Y.M. Zhu, A.J. Morton, and J.F. Nie: Philos. Mag. Lett., 2010, vol. 90, pp. 173-81.

45. Y.M. Zhu, A.J. Morton, M. Weyland, and J.F. Nie: Acta Mater., 2010, vol. 58, pp. 464-75.

46. W.W. Jian, G.M. Cheng, W.Z. Xu, H. Yuan, M.H. Tsai, Q.D. Wang, C.C. Koch, Y.T. Zhu, and S.N. Mathaudhu: Mater. Res. Lett., 2013, vol. 1, pp. 61-66.

47. W.W. Jian, G.M. Cheng, W.Z. Xu, C.C. Koch, Q.D. Qang, Y.T. Zhu, and S.N. Mathaudhu: Appl. Phys. Lett., 2013, vol. 103 (13), p. 133108 .

48. M. Nishijima, K. Hiraga, M. Yamasaki, and Y. Kawamura: Mater. Trans., 2008, vol. 49, pp. 227-29.

49. K. Saito, M. Nishijima, and K. Hiraga: Mater. Trans., 2010, vol. 51, pp. $1712-14$.

50. B.C. Muddle and I.J. Polmear: Acta Metall., 1989, vol. 37, pp. $777-89$.

51. J.F. Nie and B.C. Muddle: Mater. Forum, 1999, vol. 23, pp. $23-40$.

52. J.F. Nie, B.C. Muddle, H.I. Aaronson, S.P. Ringer, and J.P. Hirth: Metall. Mater. Trans. A, 2002, vol. 33, pp. 1649-58.

53. L. Reich, M. Murayama, and K. Hono: Acta Mater., 1998, vol. 46, pp. 6053-62.

54. B.M. Gable, G.J. Shiflet, and E.A. Starke: Metall. Mater. Trans. A, 2006, vol. 37, pp. 1091-1105. 